\title{
The Complexity and Fear of Teaching the "Other": The Role of Teachers in a Larger Process of Social Cohesion and Peace
}

\section{Sreemali M. Herath*}

${ }^{1}$ Postgraduate Institute for English (PGIE), Open University of Sri Lanka, Nawala, Sri Lanka

\section{Abstract}

Based on a narrative case study conducted in two in-service teacher preparation programs for English language teachers in Sri Lanka, this paper explores the role of English language teachers in promoting social cohesion and peace. Set against Sri Lanka's National Policy on Social Cohesion and Peace (2008), which recognizes teacher agency and teacher education in actively working towards bridging the estranged Sri Lankan communities, this paper critically analyzes what it takes for teacher education to prepare prospective teachers to be cultural brokers who are willing and able take an active role in promoting social cohesion and peace. The paper argues that national and program level policies and curricula changes are insufficient if micro level and more personal efforts are not made to assist new teachers to develop more inclusive mindsets.

Conceptually this paper is grounded on transformative approaches to pedagogy that highlight the agency of teachers and the need for teacher preparation programs to support new teachers to shape and craft their emergent transformative practices. Such approaches to teacher education identify teachers as transformative intellectuals whose role is recognized as being in tune with their social, political

\footnotetext{
* Corresponding should be addressed to Dr. S. M. Herath, Post Graduate Institute of English, The Open University of Sri Lanka, Nawala, Sri Lanka
}

Email: smher@ou.ac.lk

(D) https://orcid.org/ 0000-0002-7403-7346

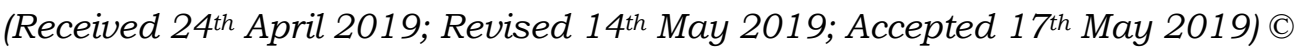
OUSL 
and historical realities. This perspective aligns with an approach in which the teacher's role extends beyond the mere transmission of knowledge and skills in the classroom to a broader, more inclusive vision of the whole socio-educational process.

The paper argues how national policies, curricula interventions, and the creation of a multicultural teacher community by diversifying the pool of prospective teachers to provide greater opportunities for intercultural interactions are insufficient if personal efforts are not made by teacher education programs and teacher educators to ensure that the program provides prospective teachers the theoretical lenses to make sense of their experiences with those who are different from them. Instead, mere cultural immersion lacking active measures that provide teachers with attitudes and skills to embrace diversity, results in the recreation of the existing status quo and promoting further mistrust among communities.

Keywords: language teacher education, language teachers, social cohesion, peace, transformative pedagogies

\section{Introduction}

The relationship between educational systems and conflict often poses a conundrum. It is a complex and multidirectional relationship. That is because education systems, more so than other social systems, have a unique and crucial role to play in rebuilding or shattering further the communities that were in conflict. This paper focuses on the education of pre-service English language teachers and whether the preparation of teachers lends itself positively to the larger processes of social cohesion and peace implemented being in Sri Lanka. By tapping into to data 'generated' (Mason, 2015) through life history narratives of culturally and linguistically diverse pre-service English language teachers in two teachers' colleges located in the Western and Central provinces of Sri Lanka, the study explores who English language teachers are, their experiences in the program and how these experiences shape their perceptions of other communities. Conceptually grounded in transformative pedagogies, the paper looks at teacher agency and the teachers' role in crafting transformative practices that extend teaching beyond preparing students for exams. 


\section{Review of literature}

The literature reviewed for this paper is drawn from two larger areas in education: Education for social cohesion and peace, and policies that were aimed and geared towards promoting sustainable peace. They lend themselves towards the study by providing a deeper and more nuanced understanding of how educational policies and structures play a role in promoting or curtailing peace and helping educators to develop more inclusive mindsets.

\section{Education, social cohesion and peace}

The assumption that education is regarded as a panacea for a broad spectrum of social ills is based on the premise that formal education can shape the understandings, attitudes and, ultimately, the behavior of individuals. However, it must be noted that such shaping can produce negative or even harmful effects. Education can, in fact, exacerbate ethnic hostilities and tensions through uneven access to education, the use of education as a cultural weapon, the manipulation of history, curriculum and textbooks for political purposes, and the segregation of education to ensure inequality and stereotyping. Thus, as a socially constructed phenomenon, education can have a destructive impact on intergroup relations (Bush and Saltarelli, 2000). Schools can also be complicit in conflict by reproducing skills, values, attitudes, and social relations of the dominant group in society, reproducing the existing status quo and perpetuating particular versions of history (Buckland, 2005; Christie and Collins, 1984; Herath; 2013, Kallaway, 1984). Moreover, there is the potential risk of educators becoming pawns of political powers (Vongalis-Macrow, 2007) and of education reinforcing the wider social and political structures that are a part of the conflict (Davies, 2010).

The other side of this argument views education as a critical player in reconciliation which has the potential of reducing the risk of relapsing into conflict. The understanding is that a solid education system can help build stronger resilience against conflict and a solid foundation for post-conflict reconciliation (Bush and Saltarelli, 2000; Minow, 1998; O'Malley, 2010; Parmar et al., 2010; Paulson, 2011a, 2011b, 2011c; Smith and Vaux, 2003; Vargas-Baron and Alarcon, 2005), and 
that it has the power to shape the understandings, attitudes, dispositions and behaviors of individuals. Education can provide opportunities to dampen the impact of the conflict, nurture and sustain an ethnically tolerant climate, desegregate minds, foster linguistic tolerance, cultivate inclusive citizenship, and disarm history. Therefore, in post-conflict times, education can be utilized to make a socially constructive impact on intergroup relations in post-conflict situations (Bush and Saltarelli, 2000). This understanding of education extends to the education and the preparation teachers as well. In a discussion about the importance of teachers being well equipped to address issues pertaining to diversity, Jim Cummins (1997) argues that teacher education programs can discriminate systemically against diverse students when teachers are ill-equipped to teach.

The consequences of discrimination in Sri Lanka, the inability of the two major ethnic communities, the Sinhalese and the Tamil, to communicate, and their subsequent polarization and estrangement resulted in a war that affected every aspect of social life and stunted the country's development and economic growth for decades have been depicted as negative features of the Sri Lankan education system which have contributed to fuelling ethnic tensions in the country (MoE, 2006; Lopes Cardozo, 2008; Bush and Saltarelli, 2000; Colenso, 2005). Ethnically segregated education in Sri Lanka, for instance, which educates children from different ethnic and religious groups separately, has led to limited interethnic interaction and tolerance (Lopes Cardozo, 2008).

Against such a backdrop, teacher education programs have a special role to play in preparing prospective teachers who are willing and able to bring estranged ethnic communities together. In the aftermath of a war, teachers who are well equipped to meet the needs of diverse learners can function as cultural brokers or ambassadors. Unlike other teachers who teach various subjects in first languages, English language teachers are uniquely positioned as teachers of the "Link Language". They are not compelled to teach in schools in their own first languages but can teach in schools where other languages are the medium of instruction. 


\section{Social cohesion and policy in Sri Lanka}

A vision to unite and reconcile local communities was presented in Sri Lanka's National Goals of Education in the First Report of the National Education Commission in 1992. Some of the clauses that pertain to building unity, equality, social cohesion and peace are as follows:

1. Nation building and the establishment of a Sri Lankan identity through the promotion of national cohesion, national integrity, national unity, harmony, and peace, and recognizing cultural diversity in Sri Lanka's plural society within a concept of respect for human dignity.

2. Creating and supporting an environment imbued with the norms of social justice and a democratic way of life that promotes respect for human rights, awareness of duties and obligations, and a deep and abiding concern for one another.

3. Fostering attitudes and skills that will contribute to securing an honorable place in the international community, based on justice, equality and mutual respect.

4. Active partnership in Nation Building activities should ensure the nurturing of a continuous sense of deep and abiding concern for one another. (National Education Commission, 2003).

These 1992 National Goals of Education were followed by the propositions of the General Education Reforms of 1997, which put a greater emphasis on pre-service and in-service teacher education in promoting social cohesion. Some areas that were promoted through teacher education reforms included promoting social cohesion and peace, human values, human rights, national cohesion, and democratic principles. Moreover, Sri Lankan teachers were expected to develop skills of empathetic listening and democratic leadership, while developing children's self-esteem and conflict resolution skills through role plays (Social Cohesion and Peace Education Unit, 2008).

Reforms in 1997 stipulated the creation of the Social Cohesion and Peace Education Unit (SCPEU) within the Ministry of Education. This development reflects the importance given to education in achieving 
national goals toward peace. It also highlights the Sri Lankan government's recognition of the need to centralize the various initiatives that are geared toward peace. The SCPEU's mandate is to provide stronger assistance and guidance to the education sector in implementing peace education initiatives in schools.

Then, in 2003, the National Policy Framework on General Education in Sri Lanka (National Education Commission, 2003) also included clauses pertaining to peace and social cohesion. This document was followed by the Education Sector Development Framework and Programme of 2006 which includes four themes. Theme 2, Improving Education Quality, focuses on promoting values, ethics, civic consciousness and social cohesion in schools. Against a backdrop of segregated education, it recognizes the role of teachers as mediators who act as models for non-violence, democracy and the promotion of rights, and who actively engage in peace building (Ministry of Education, 2006).

In 2008, the National Policy and Comprehensive Framework of Actions on Social Cohesion and Peace Education (SCPE) was presented by the Education and Social Cohesion Unit of the Ministry of Education of Sri Lanka. This policy intervention stemmed from the perceived need among government to implement a coherent and well-coordinated peace education initiative. The policy is centered in the Social Cohesion and Peace Education Unit (SCPEU) of the Ministry of Education. The SCPE initiative identified seven strategic areas and activities that needed to be introduced to the entire education system. One of the seven strategic areas include teacher education. A review of this policy in 2016 found that schools viewed social cohesion as a mere celebration of other cultures and opposed to developing a deeper understanding of other cultures (Davies et al., 2016).

What is evident from the review of policy on social cohesion and peace is that consecutive governments have recognized the role of education in peace building and more importantly the role of teachers and teacher education. However, to what extent these policies are a reality is tied to how they have trickled down to teacher education and classroom practitioners. 


\section{Theoretical framework: Transformative pedagogies}

The theoretical basis for this paper is grounded in transformative pedagogies. Transformative pedagogies can be better understood when it is framed within orientations to pedagogy. Cummins $(2009,2004$; Skourtou et al., 2006; Cummins et al., 2011) presents three broad orientations to pedagogy: transmission, social constructivist, and transformative. As depicted in Figure 1, in this formulation, the three pedagogies are nested within each other in such a way that they are understood as interconnected and codependent rather than isolated from one another.

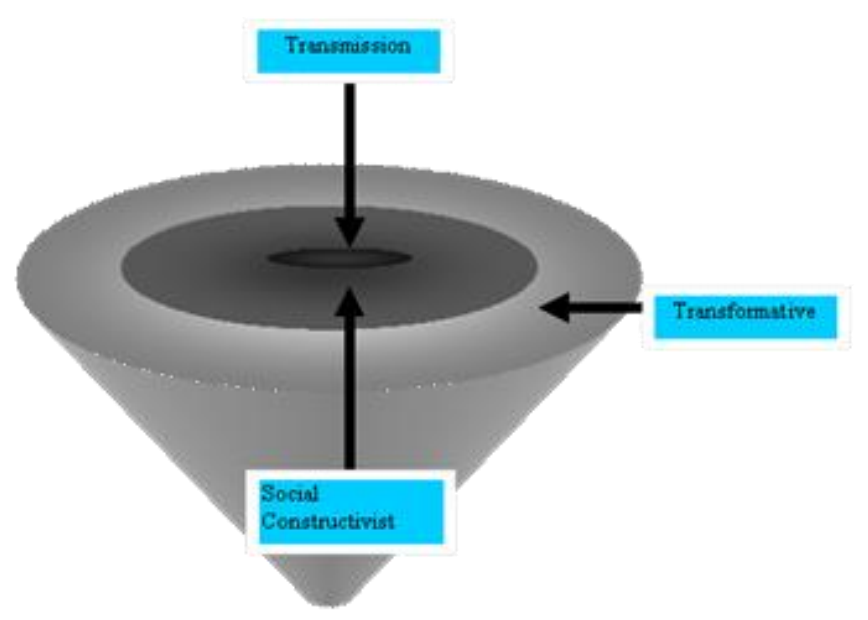

Figure 1. Nested pedagogical orientations (Cummins, 2009)

Transmission-oriented pedagogy, located at the center of the nest and occupying a small space, has the narrowest focus. Its aim is to transmit information and skills directly to students. This is similar to what Freire (1970) calls "the banking model" of pedagogy (i.e., teachers simply "deposit" knowledge into their students' "empty" minds as one would deposit money into a bank account). Exclusive reliance on a transmission approach, Cummins (2009) argues, would promote memorization rather than deep and active learning. Social constructivist pedagogy, occupying a broader pedagogical space in Cummins' nest, is located between transmission and transformative pedagogies. 
While acknowledging the importance of transmitting knowledge, constructivist pedagogy additionally focuses on "the development of higher order thinking abilities as teachers and students co-construct knowledge and understanding" (Cummins, 2009, p. 5). In this orientation, there is a focus on experiential learning, collaborative inquiry, and knowledge building.

Finally, the transformative approach to pedagogy is located in the outermost layer of the pedagogical nest, broadening the educational focus even further. It highlights the importance not only of transmitting the curriculum and constructing knowledge, but additionally, and most importantly, of enabling students to "gain insights into how knowledge intersects with power" (Cummins, 2009, p. 6). In practice, students engage with materials and undertake discussions with the purpose of identifying the types of social action they can take to change their own and others' social realities. Transformative pedagogy is attentive specially to issues of equity and justice; thus, it enables students to challenge existing power relations in society. For teachers to be transformative intellectuals, teacher education needs to have a greater emphasis on transformative orientations to pedagogy.

\section{Methodology}

This paper presents a segment of data from a much larger longitudinal study that looks at the role of language teachers in the larger processes of nation building in a post conflict situation. This paper draws on data from two residential teacher preparation programs for English language teachers offered at the National Colleges of Education in Sri Lanka (NCOE) in the Western and Central' provinces of Sri Lanka.

There are seventeen NCOE located in different provinces of the country and each college offers several subject areas of specialization in Sinhala, Tamil and English mediums. During the first two years of the program, the teacher candidates (TCs) reside in a college and take a range of courses. This provides for most of them their first experience of living and working with people from other sociocultural back-

$\dagger$ Here after these two research sites will be referred to as Central College (CC) and Western College (WC). 
grounds. Moreover, the NCOEs have a strong extracurricular component, where the TCs organize events that take place in Sri Lankan schools (such as sports days, English days, drama competitions) as well as cultural and religious festivals celebrated by the larger Sri Lankan community. During the final year, the TCs do a one-year internship in a local school.

The participants of the study consisted of final year TCs who were in the process of completing their one-year internship in schools where they were assigned the regular responsibilities of teachers. To ensure anonymity and confidentiality, all participants were given pseudonyms. To simplify the identification of which college the TCs were from (i.e., Central or Western College), TCs from the Central College (CC) were given names beginning with the letter " $\mathrm{C}$ " and those from the Western College (WC) were given names beginning with "W". As there were female and male TCs from different ethnic and religious backgrounds, they were given pseudonyms that reflected their social and cultural identities.

The use of narrative inquiry provided rich data that cannot be gathered from other forms of data collection such as questionnaires, experiments, or observations. Moreover, the uniqueness of one's own personal narrative as a researcher and that of each of the participants in a study manifests rich data. Polkinghorne (1988) claims that narrative is the "primary form by which human experience is made meaningful" (p.1). Clandinin and Connelly (1994) reiterate that, "stories are the closest we can come to experience as we and others tell of our experience" (p. 415). Participants' narratives give rich insights into their own experiences that researchers are not able to get at otherwise.

\section{Findings}

The findings of the study focus on teacher identity and who prospective Sri Lankan English language teachers are; the efforts the programs make to foster cultural awareness among its candidates; their experiences within the residential program; and how the teacher candidates report having changed as a result of these initiatives. 


\section{The NCOEs and their teacher candidates (TCs)}

Research on reconciliation and social cohesion initiatives in education highlights the need for "diversity sensitive recruitment and deployment policies" (Smith, 2005, p. 382) that ensures the adequate recruitment of teachers from different ethnic and linguistic groups. Social justice teacher education calls for the recruitment of a diverse teaching force if teacher education is to bring about broad-scale social change (Zeichner, 2011). Both WC and CC were multicultural and programs were offered in all three languages. There were TCs from diverse socio-cultural backgrounds and they came from different parts of the country.

However, a common theme that underlined the narratives of TCs from both colleges was the segregated nature of their upbringing. Many of the TCs had grown up in geographical and social settings that provided them with little exposure to other cultures. Irrespective of where they had grown up, they had not had exposure to other ethnic and linguistic communities. The following excerpts shed light on the nature of their experiences,

My primary school was a Sinhala Buddhist school in my village. Then I went to another Sinhalese Buddhist middle/high school. All the students were lower middle-class or poor. I knew only Sinhala people. (Camal)

My town is a Muslim town in the East. We are all Muslim. Life was different there. It was a different culture. I never met people from other communities before I came to college. (Waseem)

There were, however, minority Tamil and Muslim TCs who had had a greater degree of exposure to other communities.

In my old school, there were only Tamils and Muslims. There were no Sinhalese. But my hometown, Badulla, is a multicultural city. Growing up, I knew lots of Sinhalese, Tamils, Muslims and Christians. We had friends who visited us. I can speak all languages. (Withya) 
Nevertheless, such students were a minority. As a result, for many TCs, the teachers' college was their first exposure to multicultural diversity in Sri Lanka. Most of the TCs had grown up in homogenous communities.

Moreover, there were TCs like Waseem who had firsthand experiences of war:

My father is dead. He was a farmer. He was killed in 1990. The LTTE shot him and his three brothers when they were working in the field. This happened three days after my younger brother was born. I was two years old. I have four brothers and one sister, and my mother struggled to raise us. My mother is a housewife. She still cries when she talks about how she raised us. (Waseem)

On the one hand, the TCs' narratives presented nuances and rich data that highlight the segregated nature of their upbringing, on the other hand, they showcased a range of diverse experiences of growing up amidst a war. Collectively, these lived experiences can be rich resources to learn about others which the program should exploit in order to promote greater awareness of lived experiences of those from other communities. Yet the narratives of the participants reveal that personal lives, experiences and sociocultural backgrounds were never discussed or analyzed to gain a better understanding of the larger social fabric the teachers lived and worked in.

\section{Experiences in the program}

The two-year residency forced the TCs to meet people from other communities and to coexist, collaborate and learn about them. It is argued that coexistence has the potential to overcome the negative impact of segregation. It can help in overcoming the limited interethnic interactions and intolerance that is perpetuated in segregated primary and secondary education (Lopes Cardozo, 2008).

While many TCs complained about the rigor of the routine, they also spoke of the many advantages their residential training brought. Among these advantages was the fact that, for many, their college experience provided them with their first exposure to Sri Lankan multicultural diversity. 
It was very helpful for us to be with different people. We always chatted. We learned a lot about their backgrounds, customs and many things we didn't know. I will always value that experience. (Camal)

We got to meet people from different ethnic and religious groups. I grew up in the East and I didn't know Sinhalese people before. I had only seen them on TV. But in college we got involved with them. We also celebrated all Sri Lankan religious and cultural events. (Cala)

Integrated education such as the one offered in the $\mathrm{NCOE}$ is recognized as an effective means to reconcile previously conflicting communities. Providing more opportunities for intergroup contact (Donnelly and Hughes, 2009) that foster coexistence (Sampson, 2003) and encourage dialogue (Tully, 2004) can help estranged communities reconcile. Getting to know people from different social and cultural groups and receiving knowledge about them can lead toward improved attitudes (Johnson and Stewart, 2007).

The TCs also celebrated all local, cultural and religious festivals in the NCOE. The celebration of cultural events made TCs learn about other cultures outside of the formal curriculum. Yet, the mere celebration of other cultures as opposed to developing a deeper understanding of other cultures (Davies et al., 2016) did not assist in developing a deeper and more sustainable understanding of other communities that were tied to stronger principals of respect and empathy.

Camal and William spoke about the novelty of entering the teachers' college. Every aspect of life in the college, ranging from the subjects the TCs had to study, to the environment they had to live in, to interacting with their lecturers was a new experience.

It was a new experience. We come from a Sinhalese society, so when we come to the college, it's a novel experience for us. We had to talk in English. But with time, we learned what we should do. I learned a lot about other cultures and festivals. These are things I had seen on TV, but in college, I got to take part in them. (Camal) 
Living in the community was good. We celebrated Sinhalese and Tamil New Year, Ramadan, Thai Pongal, Christmas and many more festivals. Even when other religious festivals are celebrated, we join in and help. Before that I didn't know what Thai Pongal was or what food they make. I think we need the two residential years to learn all that.... Then we also met different people. In the beginning, it was difficult to remember those names. We were not used to Muslim names like Sijaam, Aashik, and Abdul. It was different for us. They also didn't know how to pronounce our names. When they did, it was funny. They were my first Muslim friends. Before going to the college, I didn't know Muslims went to the mosque on Fridays and prayed five times a day. It was interesting to learn about them. We were together for two years. They didn't know Sinhala and we didn't know Tamil. So, we spoke in English. It was hard, but we improved our English....Now, I know a lot about other cultures. I think now I can adapt to any school environment. I have the ability to accept others and adjust. (William)

Living with others different ethnicities provided a new exposure to all TCs. They got to know TCs from other cultures and experienced their festivals. It was more or less an exotic experience for them.

Although the TCs are made to coexist for two years, the formal curriculum does not explicitly address issues of diversity and the values of learning from other cultures. It is important for educational reform in post-conflict nations to construct new curricula with a broader understanding of what it means to be a nation state. It also needs to focus on the skills teachers need to have in order to create more inclusive learning environments (Shah, 2012). Merely throwing people together and expecting them to learn from each other without any explicitly knowledge conceptual lenses can prove to be counterproductive. They are not provided conceptual lenses to deconstruct and understand their experiences. Courses in human rights education, citizenship education, intercultural and peace education have the potential to foster social cohesion (Smith 2005), however, these are not taught in the NCOE. Nor does the existing curriculum attempt to raise students' critical awareness and their role beyond that of transmitting 
the curriculum. Although the Sociology of Education curriculum includes topics such as "Diversity of sociocultural background" and examines the factors that contribute to sociocultural diversity such as social class/sub classes, ethnicity, religion locality (urban/rural) and their implications for classroom practice, these topics seem to be addressed as separate topics and events rather than as ones that identify the causes, how they are interconnected and how they shape the social fabric.

Moreover, following the guidelines of the National Policy on Social Cohesion for Education and Peace (Ministry of Education, 2008) all the NCOEs carry out an Education for Social Cohesion and Peace (ESCP) program and teach Sinhala/Tamil as a Second National Language (2NL) for all TCs. But these initiatives remained mere add-ons that both teacher candidates and teacher educators viewed as a burden. The common "formal curriculum" and assignment schedule as used in all three colleges of the NCOE does not include such courses. Instead, a transmission mode of pedagogy is used to prepare the students for their examinations. While there were larger national policies and program level curricular initiatives geared towards promoting greater social cohesion, the individual programs lacked the infrastructure and the academic culture to promote and mainstream such initiatives. Most teacher educators lacked the knowledge, skills and the attitudes needed to help prospective teachers to develop more inclusive pedagogical practices. This resulted in a recreation of the existing status quo.

\section{Changing perceptions}

For future teachers to develop positive outlooks towards diversity and their agency to bring change, the teacher education program needs to have a formal curriculum and a learning environment that are conducive to multicultural initiatives which can foster positive outlooks toward diversity. Teacher education needs to provide teachers experiences that highlight their responsibility to serve as agents of change (Hawkins, 2011a) or as transformative intellectuals. What was evident in the narratives of the TCs was that many TCs developed very strong negatives stereotypes of other communities. In the absence of explicit instruction and cultural exposure that was limited to the celebration 
of cultural events, many TCs withdrew deeper into their monocultures.

Although many TCs claimed to have learned about other social and cultural groups, some also had reservations about the terms on which others could be accepted. One such line of thinking was expressed by Camal whose narrative reflected his acceptance of other social and cultural groups who accepted the dominant Sinhalese Buddhist culture he represented. While he indicated that he appreciated the exposure he received from the Sri Lankan society, he also had his reservations:

I met various people from different parts of Sri Lanka. It was a good experience for us to stay with them. There were Tamils and Muslims. Sometimes we are okay with them. Sometimes we are not. We don't accept their ways and they don't accept our ways. Sometimes when we switch the TV on for pirith, the Muslims switched it off. There are some good Muslims too. They like to learn about our culture. (Camal)

Similarly, Wansha, an upper-class Sinhalese female sympathized with rural TCs who did not possess good English skills and came to her for help. Their dependency on her for language support gave her a sense of superiority. She also stated that it gave TCs of minority backgrounds a sense of pride to return home and talk about their new friends who were from the dominant and more affluent cultures. "It's a big thing for them to have Sinhalese friends," she noted.

Both Camal's and Wansha's acceptance of others was based on how their own sense of superiority was accepted by others. They welcomed others who recognized them and accepted their dominant ways.

Although the program attempted to create an inclusive learning environment, the minorities felt marginalized. Waseem spoke of how his Muslim culture was overlooked in the program. He felt that the program expected minorities to conform to the dominant culture. As someone who thought it was his responsibility to preserve his culture for future generations, he felt the program was not helping him much. Instead, he perceived that the program fostered unequal expectations from different communities. 
There were ethnic problems. That was a place where people from all cultures and backgrounds were present. We have to respect religions and virtues. For example, we Muslims can't light lamps. Women can't dance or sing in front of men. Women can't be running, even in phys ed. They need to respect our religion. We can't destroy our religion, our virtues and our culture. We have to save it and transfer it to the next generation as our previous generations did for us.

They [the Sinhalese] expect us to speak in Sinhalese, and when we do speak, we don't speak properly. We have a different accent. They feel insulted. But they don't try to learn our language. That's how it is. (Waseem)

Waseem felt, the immersion experience was imbalanced and was more about enforcing the dominant culture.

The experience in the NCOE program also promoted sentiments among majority TCs such as Chintha, who felt the Sinhalese culture was being taken for granted and that the Sinhalese, unlike the other groups, were not united.

When I was in college, I thought, "It's not good to discriminate." But later, I thought I needed to change my ideas. Sinhalese have only this country. Tamils have Tamil Nadu [In India]. Muslims can go to Pakistan or Arabic countries. After I went to college, I realized that we needed to stand up as Sinhalese. They [minorities] are competing with us. They want to go beyond the Sinhalese. I don't want to discriminate. But my experiences have taught me there needs to be discrimination. (Chintha)

Chintha's multicultural experiences prove to be counterproductive. Though not explicitly stated by the other TCs, the fact that most of the TCs chose schools from their own backgrounds for their one-year internship indicates that they were neither willing nor ready to take up the challenge of teaching students from other communities.

Withya, for instance stated that her choice of the internship school was tied to her belief in the English language teacher's ability to speak 
the first language of the students. This is partly shaped by negative teaching practice experiences that were not well mentored.

Teaching Sinhalese students was not easy. When I did my block teaching in Sinhalese schools, the students were very weak. They couldn't understand anything I said in English. I speak Sinhalese well, but when I spoke in Sinhalese, they laughed at my Tamil accent. When I spoke in English, they couldn't understand me. That's a big problem. It's hard to make them understand. It's hard to get them to do tasks. If you have to explain a word like "enthusiasm," knowing the L1 helps. (Withya)

Similarly, while sharing his experiences of doing his internship in a Muslim school, Waseem stated "I am very proud of myself for serving my own community." Irrespective of their backgrounds, the TCs were more comfortable returning to their own communities. They felt more comfortable and accepted to work in their own communities.

\section{Discussion}

Although policy formulations and educational reforms are an important first step in post-conflict reconciliation, ultimately teachers are the ones who have to implement these changes. The history of policy and their evolution in Sri Lanka shows that successive governments have identified the role of education and particularly teacher education in the larger processes of reconciliation. However, policies have remained dead letters with little impact. There aren't steps taken, such as developing and implementing comprehensive teacher education programs that stand in contrast to the old, to ensure these policies are a reality. Instead the teacher education curriculum has remained static. If larger structural changes that prepare teachers who have the agency, knowledge and skills to be change agents who are able to challenge exclusionary and biased values are to take place, the old curriculum needs to be replaced with a new one. Prospective teachers need to first be aware of the existing educational policies and secondly, they need to be aware of their role in the nation's reconciliation process.

Most literature on diversity in teacher populations (Swartz, 2003; Zeichner and Hoeft, 1996) highlights the homogeneity of teachers and 
points out the discrepancy in backgrounds between teachers and learners. Contrary to this picture, however, the TCs in the NCOE in Sri Lanka, overall, consisted of teachers from all the country's ethnic, linguistic and religious backgrounds. There were also TCs from urban and rural areas from different parts of the country. Diversity of teachers, on the one hand, ensures that teachers are representative of their students. In a segregated educational environment like Sri Lanka, there are teachers from diverse backgrounds who can function as cultural brokers. They can work in schools that are different from their own backgrounds and thus provide the students with opportunities to learn from a teacher who is from a background different to theirs. It is the role of teacher education to ensure that diversity is seen as a strength and a resource to promote greater sociocultural awareness. This awareness cannot come about merely from an immersion experience, rather, it needs to be tied to explicit instruction and dialogue where prospective teachers formulate new understandings of what it means to live and work in a multicultural society. They need to be able to recognize the need to live together peacefully, by recognizing the other and by overcoming prejudices within the individual and between individuals and communities.

The biggest barrier is the NCOEs' transmission-oriented curriculum that does not make explicit the role of the teachers to be change agents. On the one hand, the curriculum does not include courses that explicitly talk about social justice, peace, multiculturalism that can help TCs to understand and value diversity as well as their own roles. The TCs are not provided with conceptual frameworks or skills to make sense of the diversity they experience inside and outside the class. The TCs are neither given the knowledge nor the space to talk about their evolution and growth during the program so they can formulate a newer and broader understanding of other communities as well as their roles as change agents. This results in TCs regressing more into their own communities and forming negative stereotypes of other communities.

As the research on teacher education programs in different post-conflict contexts shows, education has a unique capacity to provide opportunities for post-conflict societies to dampen the impact of the con- 
flict they have endured (Bush and Saltarelli, 2000). For these transformations to become a truly effective and concrete social reality, however, teachers need explicit instruction that is built into every aspect of their program. Courses in subjects such as Peace and Citizenship Education need to occupy a position that is higher up on the teacher education agenda (Davies, 2005). The manner in which post-conflict states manage, deliberate and execute transformative initiatives is crucial in changing the fragile social conditions that are the legacy of conflict situations (Davies, 2010; Paulson, 2011d).

\section{References}

Buckland, P. (2005). Reshaping the future: Education and post conflict reconstruction. Washington, DC: World Bank.

Bush, K. \&Saltarelli, D. (2000). The two faces of education in ethnic conflict: Towards a peacebuilding education for children. Florence: UNICEF.

Christie, P. \& Collins, C. (1984) Bantu education: Apartheid ideology and labour production. In P. Kallaway (ed.) Apartheid and education: The education of Black South Africans (pp.160-179). Johannesburg: Ravan Press.

Colenso, P. (2005) 'Education and social cohesion: developing a framework for education sector reform in Sri Lanka', Compare: A Journal of Comparative and International Education, 35 (4): 411428.

Cummins, J. (1997). Cultural and linguistic diversity in education: a mainstream issue. Education Review, 49(2), 105-114.

Cummins, J. (2009). Transformative Multiliteracies Pedagogy: School-Based Strategies for Closing the Achievement Gap. Multiple Voices for Ethnically Diverse Exceptional Learners, 112, 38-56.

Cummins, J. (2004). Multiliteracies pedagogy and the role of identity texts. In K. Leithwood, P. McArdie, N. Bascia, \& A. Rodigue (Eds.) Teaching for deep understanding: Towards the Ontario curriculum that we need. Toronto: Ontario Institute for Studies in Higher Education of the University of Toronto and the Elementary Federation of Teachers of Ontario. 
Cummins, J. Early, M. \& Stille, S. (2011). Frames of reference: Identity texts in perspective. In J. Cummins and M. Early (Eds.) Identity texts: The collaborative creation of power in multilingual schools (pp. 21-43). Stoke on Trent, UK: Trentham Books.

Davies, L. (2005). Teaching about conflict through citizenship education. International Journal of Citizenship and Teacher Education, 1(2), 17-34.

Davies, L. (2010) 'The Different Faces of Education in Conflict', Development, 53 (4): 491-497.

Davies, L., Herath, S. \& Sethunga, P. (2016). The National Policy on Education for Social Cohesion and Peace: Strategies towards sustainable peace. Colombo: Ministry of Education, Sri Lanka.

Donnelly, C. \& Hughes (2009). Contact and culture: Mechanisms of reconciliation in schools in Northern Ireland and Israel. In J.R. Quinn (ed). Reconciliation(s): Transnational justice in postconflcit societies. (pp. 147-174), Montreal: McGill-Queen's University Press.

Freire, P. (1970). Pedagogy of the oppressed. New York: Continuum.

Giroux, H. A. (1988). Teachers as intellectuals: towards a critical pedagogy of learning. Granby, MA: Bergin \& Garvy.

Hawkins, M. (2011a). Introduction. In M. Hawkins, (Ed.) Social justice language teacher education (pp. 1 - 6). Bristol: Multilingual Matters.

Herath, S. (2013). Accommodating diversity in English language teaching (ELT) material: The impact on Sri Lankan textbooks. In S. May (Ed.), LED2011: Refereed conference proceedings of the 3nd International Conference on Language, Education and Diversity. Auckland, New Zealand: University of Auckland.

Johnson, D. \& Stewart, F. (2007). Education, Ethnicity and conflict. International Journal of Educational Development, 27, 247-251.

Kallaway, P. (Ed.) (1984). Apartheid and education: The education of Black South Africans. Johannesburg: Ravan Press.

Lopes Cardozo, M. T. A. (2008) 'Sri Lanka: in peace or in pieces? A Critical Approach to Peace Education in Sri Lanka', Research in Comparative and International Education, 3 (1):19-35. 
Mason, J. (2005). Qualitative researching. London: Sage Publications. Ministry of Education (MoE) (2006) Education Sector Development Framework a Programme. Colombo: Planning and Performance Review Division, Isurupaya.

Minow, M. (1998). Between vengeance and forgiveness: Facing history after genocide and mass violence. Boston: Beacon Press.

National Education Commission (2003). Proposals for a national policy framework on general education Colombo: National Education Commission, Sri Lanka.

Parmar, S., Roseman, S. M., Siegrist, S., \& Sowa, T. (eds.) (2010). Children and transitional justice: Truth telling accountability and reconciliation. Cambridge, MA: Harvard University Press.

Paulson, J. (ed.) (2011a). Education and reconciliation: Exploring conflict and post-conflict situations. London: Continuum International Publishing Group.

Paulson, J. (ed.) (2011b). Education conflict and development. Oxford: Symposium Books Ltd.

Paulson, J. (2011c). Introduction: Education and reconciliation. In J. Paulson (Ed.) Education and reconciliation: Exploring conflict and post-conflict situations (pp. 1-10). London: Continuum International Publishing Group.

Paulson, J. (2011d). Reconciliation through educational reform? Recommendations and realities in Peru. In J. Paulson (Ed.) Education and reconciliation: Exploring conflict and post-conflict situations (pp. 126-150). London: Continuum International Publishing Group.

Polkinghorne, D. (1988). Narrative knowing and the human sciences. Albany, NY: State University of New York Press.

O’Malley, B. (2010). Education under attack. Paris: UNESCO.

Sampson, S. (2003). From reconciliation to coexistence, Public Culture, 15(1), 181-186.

Shah, R. (2012). Goodbye conflict, hello development? Curriculum reform in Timor-Leste. International Journal of Educational Development, 32, 31-38. 
Skourtou, E., Kourtis-Kazoullis, V. \& Cummins, J. (2006). Designing virtual learning environments for academic language development. In J. Weiss, J. Nolan, J. Hunsinger \& P. Trifonas (Eds.) The international handbook of virtual learning environments. Dordrecht: Springer.

Social Cohesion and Peace Education Unit (2008). National Policy and Comprehension Framework of Actions of Social Cohesion for Education and Peace (ESCP). Colombo: Ministry of Education.

Smith, A. (2005). Education in the twenty-first century: Conflict, reconstruction and reconciliation. Compare, 35(4), 373-391.

Smith, A. \& Vaux, T. (2003). Education, conflict and international development. London: DFID

Swartz, E. (2003). Teaching White pre-service teachers: Pedagogy for change. Urban Education, 38, 255-278.

Tully, J. (2004). Reconciliation and dialogue: The emergence of a new filed. Critical Review of International Social and Political Philosophy, 7(3), 84-106.

Vargas-Baron, E. \& Alarcon, H. (eds.) (2005). From bullets to blackboards: Education for peace in Latin America and Asia. Washington, DC: Inter-American Development Bank.

Vongalis-Macrow, A. (2007) 'I, Teacher: re-territorialization of teachers' multi-faceted agency in globalized education', British Journal of Sociology of Education, 28(4): 425-439.

Zeichner, K. (2011). Teacher education for social justice. In M. Hawkins (Ed.) Social justice language teacher education (pp. 7 22). Bristol: Multilingual Matters.

Zeichner, K. M. \& Hoeft, K. (1996). Teacher socialization for cultural diversity. In S. Y. Buttery \& E. Guyton (Eds.) Handbook of research on teacher education (2nd Ed.). (pp. 525-547). New York: Macmillan. 